\title{
MAPEAMENTO DE ÁREAS SUSCETÍVEIS À INUNDAÇ̃̃O COMO INFORMACÃO PARA O PLANEJAMENTO E A GESTÃO TERRITORIAL EM BACIA HIDROGRẢFICA
}

\author{
Marlon Domingos Cury \\ Universidade Federal dos Vales do Jequitinhonha e Mucuri (UFVJM), Teófilo Otoni, MG, Brasil \\ marlon.dcury@gmail.com \\ Nilzo Ivo Ladwig \\ Universidade do Extremo Sul Catarinense (UNESC) \\ Pós Graduação em Ciências Ambientais, Criciúma, SC, Brasil \\ ladwig@unesc.net
}

Juliana Debiasi Menegasso

Universidade do Extremo Sul Catarinense (UNESC)

Pós Graduação em Ciências Ambientais, Criciúma, SC, Brasil

julianaorleans@gmail.com

Thaise Suti

Universidade do Extremo Sul Catarinense (UNESC)

Pós Graduação em Ciências Ambientais, Criciúma, SC, Brasil

thaise.sutil@gmail.com

Danrlei de Conto

Universidade do Extremo Sul Catarinense (UNESC)

Pós Graduação em Ciências Ambientais, Criciúma, SC, Brasil

danrleideconto@hotmail.com

\section{RESUMO}

Eventos extremos como as inundações têm-se intensificado, tornando-se cada vez mais frequentes, causando prejuízos socioeconômicos. A utilização da cartografia de suscetibilidade à inundação é um importante subsídio para o planejamento e gestão territorial, pois facilita a visualização e interpretação das predições de eventos extremos. A pesquisa tem como objeto de estudo a bacia hidrográfica e como objetivo analisar a suscetibilidade de inundação no domínio do seu limite geomorfológico. Os condicionantes considerados na definicão das áreas suscetíveis à inundação foram declividade, altimetria, ordem dos rios (baseada nas ottobacias) e uso e cobertura da terra. Na definição dos pesos dos condicionantes utilizou-se o Método de Análise Hierárquica de Processos em ambiente de Sistema Geográfico de Informações. Os resultados revelaram que a bacia hidrográfica do Rio Urussanga possui aproximadamente $30 \%$ de áreas com alta suscetibilidade à inundação, abrangendo grande parte das cidades de Balneário Rincão, Criciúma, Içara, Jaguaruna e Morro da Fumaça. As regiões de menor suscetibilidade à inundação encontram-se nas linhas divisoras de água da bacia, onde predominam as maiores altitudes e declividades. Por fim, o mapeamento possibilitou a utilização dessas informações para determinar áreas prioritárias para a tomada de medidas mitigadoras e prevenção dos impactos negativos decorrentes de eventos de inundação.

Palavras-chave: Hidrografia. Cartografia. Geoprocessamento.

\section{MAPPING OF AREAS SUSTAINABLE TO FLOODING AS INFORMATION FOR PLANNING AND TERRITORIAL MANAGEMENT IN A HYDROGRAPHIC BASIN}

\begin{abstract}
Extreme events such as floods have intensified, becoming more and more frequent, causing socioeconomic losses. The use of flood susceptibility cartography is an important subsidy for territorial planning and management, $\mathrm{o}$ it facilitates the visualization and interpretation of predictions of extreme events. The research has as its object of study the hydrographic basin and its objective is to analyze the susceptibility of flooding in the domain of its geomorphological limit. The conditions considered in the definition of areas susceptible to flooding were declivity, altimetry, order of rivers (based on ottobacias) and land use and coverage. In the definition of the weights of the conditioning factors, the Hierarchical Process Analysis Method was used in a geographic information system environment. The results revealed that the Urussanga River basin has approximately $30 \%$ of areas with high susceptibility to flooding, covering a large part of the cities of Balneário Rincão, Criciúma, Içara, Jaguaruna and Morro da Fumaça. The regions with the least susceptibility to flooding are found in the watershed dividing lines of the basin, where the highest altitudes and slopes
\end{abstract}


predominate. Finally, the mapping made it possible to use this information to determine priority areas for taking mitigating measures and preventing negative impacts resulting from flooding events.

Keywords: Hydrography. Cartography. Geoprocessing.

\section{INTRODUÇÃO}

As mudanças climáticas produzem crescente complexidade e incerteza frente às consequências em todos os sistemas existentes. Complexidade entendida como "um tecido de constituintes heterogêneos inseparavelmente associados: ele coloca o paradoxo do uno e do múltiplo" (MORIN, 2011, p.17). As mudanças climáticas impactam o ciclo hidrológico e são agravadas por questões globais como a pobreza, podendo aumentar a frequência de eventos extremos como as inundações.

As mudanças climáticas terão papel relevante na ocorrência de extremos hidrológicos, responsáveis por afetar populações humanas em razão de desastres, como enchentes, deslizamentos e transbordamentos nas várzeas (TUNDISI, 2008). No Brasil, eventos extremos como as inundações e os deslizamentos têm se intensificado e tornando-se cada vez mais frequentes, afetando áreas urbanas e ribeirinhas, causando prejuízos sociais e econômicos (CURY, 2018).

As condições físicas do ambiente, como o tipo de terreno, a hidrografia, a morfometria e a topografia, definem as áreas como naturalmente suscetíveis a inundação (DANTAS, 2018). Contudo, Menegasso (2019) ressalta que, apesar do termo suscetibilidade induzir as características físicas do ambiente, as alterações antrópicas são consideradas agentes intensificadores da suscetibilidade às inundações.

Segundo Borges (2013), as cheias e as inundações são eventos naturais que ocorrem nos cursos d'água, possuindo um período de retorno em decorrência de chuvas fortes e rápidas ou de longa duração. Porém, as atividades antrópicas contribuem para a maior ocorrência, sobretudo se conjugados fatores sociais como o crescimento significativo da urbanização desordenada, a expansão da indústria, o desenvolvimento do agronegócio, a exploração intensiva do solo e ocupação das zonas ribeirinhas; agravados ainda pela alteração climática e o aquecimento global.

Para Amaral e Ribeiro (2012), são condicionantes naturais dos processos de inundação as formas de relevo, característica da drenagem da bacia hidrográfica, intensidade, quantidade, distribuição e frequência das chuvas, características do solo e o teor de umidade, presença ou ausência da cobertura vegetal.

Os autores corroboram com Borges (2013) ao exemplificar condicionantes antrópicas que podem potencializar ou acelerar os processos de inundação, como a impermeabilização do solo, a retificação, desvios e canalização de cursos d'água e a construção de barragens para diferentes fins como o acúmulo de rejeito de mineração, reservatório de água para abastecimento e produção de energia.

De acordo com Ladwig e Rosso (2015) o uso do geoprocessamento para diagnóstico de risco, tomada de decisão em planejamento e gestão territorial é crescente no país. O fato de conhecer e visualizar onde as áreas suscetíveis aos desastres ocorrem, espacialmente, na forma de mapa temático, facilita o entendimento e aumenta a percepção do problema trabalhado.

Para Assad e Sano (2003), os sistemas geográficos de informações (SIGs) são uma das técnicas mais eficientes para o tratamento de informações espaciais, que podem ser definidos como um sistema destinado ao tratamento automatizado de dados georreferenciados, com a capacidade de manipular dados de diversas fontes e formatos dentro de um ambiente computacional. Ainda para o autor, o uso destas ferramentas pode ser empregado no planejamento territorial da área estudada.

Ladwig e Gonçalves (2014) complementam ao dizer que uma base de dados consistente possibilita a análise e o mapeamento de uma região objetivando uma medida mais eficaz na prevenção, proteção e mitigação dos impactos negativos dos desastres. Assim, a realização de um mapeamento de áreas suscetíveis à inundação, pode ser considerada uma importante medida não estrutural, no planejamento e na gestão do risco a desastres hidrológicos (REIS et al., 2014).

A pesquisa tem como objeto de estudo a bacia hidrográfica do Rio Urussanga (BHRU), Santa Catarina, Brasil. A BHRU, de acordo com o estudo de Cury (2018), emitiu, entre os anos de 1998 e 2017, 81 decretos associados à inundação, enxurradas ou chuvas intensas, sendo classificados como situação de emergência. Assim, o objetivo deste trabalho é analisar áreas suscetíveis à inundação no domínio do seu limite geomorfológico.

Caminhos de Geografia Uberlândia-MG $\quad$ v. 22, n. $83 \quad$ out./2021 p. 160-175 Página 161




\section{Localização e caracterização da área de estudo}

A BHRU está inserida na Região Hidrográfica ( $\mathrm{RH} 10)$, localizada no Sul do estado de Santa Catarina, conforme a lei $n^{\circ}$ 10.949/1998, que dispõe sobre a caracterização do estado em dez Regiões. (Figura 1). A BHRU possui uma área territorial de $679,687631 \mathrm{~km}^{2}$, correspondendo a $67.968,7631 \mathrm{ha}$. E abrange em seu território dez municípios.

Figura 1 - Mapa de localização da Bacia Hidrográfica do Rio Urussanga, Santa Catarina.

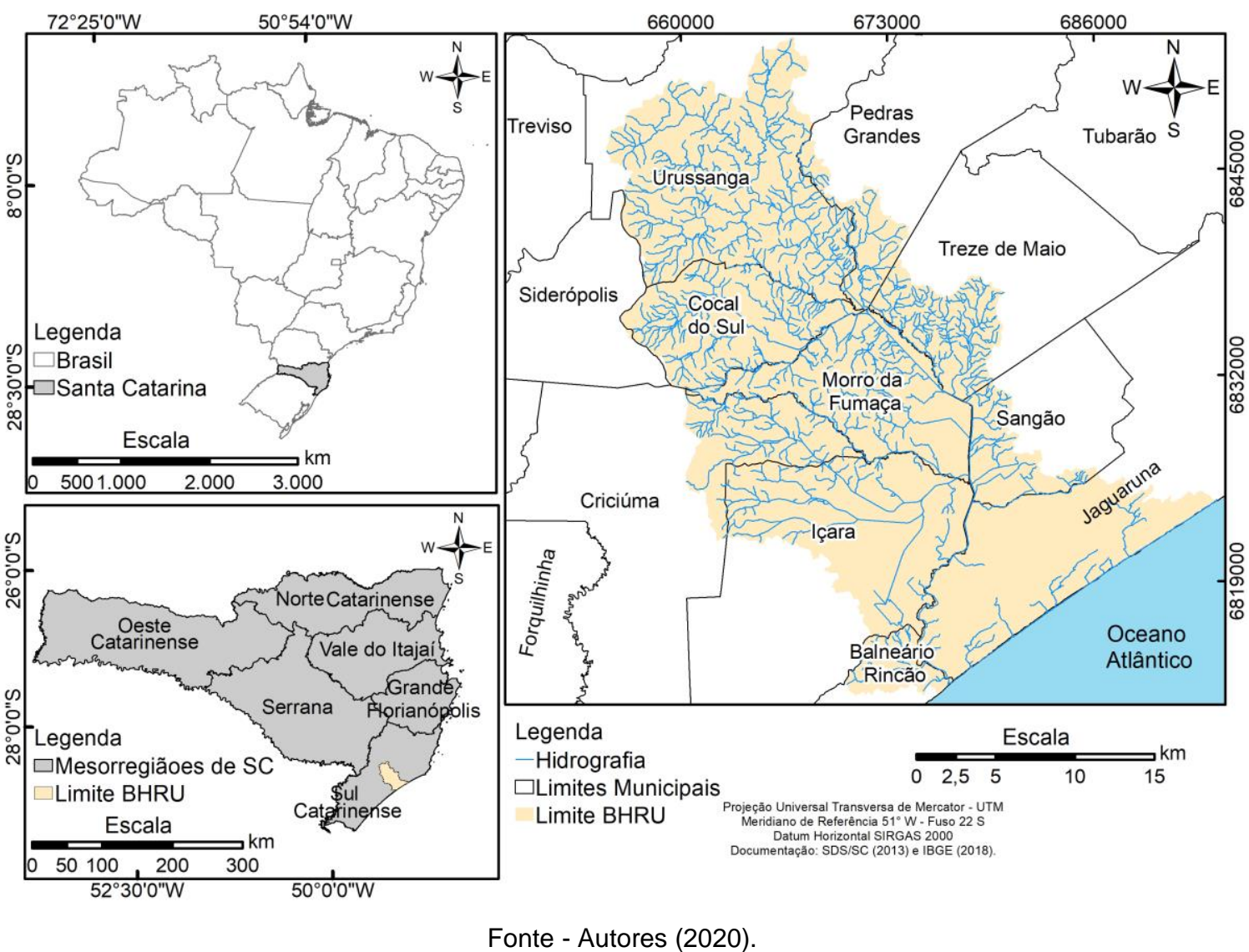

Destes, dois estão totalmente inseridos nos limites da bacia hidrográfica - os municípios de Cocal do Sul e Morro da Fumaça e os municípios de Balneário Rincão, Criciúma, Içara, Pedras Grandes, Treze de Maio, Sangão, Jaguaruna e Urussanga estão parcialmente inseridos.

O tipo climático da área de estudo, segundo a classificação climática de Köppen, é o Cfa. O índice pluviométrico varia de 1220 a 1660 mm, com 102 a 150 dias de chuvas anuais, e umidade relativa do ar com uma variação entre $81,4 \%$ a 82,2\% (PANDOLFO et al., 2002; BACK, 2009).

Segundo o IBGE (2012) a vegetação da área de estudo é composta pela Floresta Ombrófila Densa e nas faixas litorâneas, em menor proporção, formação pioneira (Restingas).

$\mathrm{Na}$ região sul catarinense as atividades agrícolas, a pecuária e a extração de carvão mineral atuaram sinergicamente para a degradação ambiental da Bacia Hidrográfica do Rio Urussanga. De acordo com Menezes e Waterkemper (2009), extensas áreas foram degradadas e tiveram seus recursos naturais comprometidos devido às lavras de carvão, tanto a céu aberto quanto subterrânea, poluindo as águas, contaminando o solo e invadindo terras agricultáveis.

A bacia hidrográfica do Rio Urussanga apresenta uma configuração, quando deságua no Oceano Atlântico, com características de delta e engloba pequenas bacias hidrográficas litorâneas. A bacia possui $17 \%$ dos seus rios comprometidos pela mineração do carvão, totalizando $256,8 \mathrm{~km}$ de curso hídrico. Em $161,6 \mathrm{~km}$ o pH se encontra em intervalos abaixo dos 4,5 (UFSC, 2016).
Caminhos de Geografia
Uberlândia-MG
v. 22, n. 83
out./2021
p. $160-175$
Página 162 


\section{METODOLOGIA}

A pesquisa bibliográfica utilizou materiais que já foram publicados, como livros, artigos científicos, teses e dissertações (PRODANOV e FREITAS, 2013; MENEZES et al., 2019). Esta etapa foi fundamental na escolha dos condicionantes para mapear as áreas suscetíveis à inundação, sendo eles: hipsometria, declividade, uso e cobertura da terra e ordem dos rios. Além disso, permitiu se apropriar e adaptar metodologias diferenciadas na identificação e delimitação de áreas suscetíveis a inundação.

A outra etapa deste trabalho consistiu em uma pesquisa documental. Zanella (2013) e Prodanov e Freitas (2013) afirmam que a pesquisa documental é aquela que utiliza fontes documentais, que não receberam métodos de análise. Neste caso, buscaram-se dados espaciais georreferenciados no Instituto Brasileiro de Geografia e Estatística (IBGE, 2018) e na Secretaria de Estado de Desenvolvimento Sustentável de Santa Catarina (SDS, 2013)

$\mathrm{Na}$ estruturacão da base cartográfica foram utilizados arquivos em formato matricial e vetorial disponibilizados pela SDS, datadas do ano de 2011. A base de dados espaciais compreendeu imagem ortorretificada, composição RGB com resolução espacial de 0,37 metros, modelo numérico do terreno (MDT) e modelo numérico de superfície (MDS) e rede hidrográfica ottocodificada. Cabe aqui uma observacão, os dados espaciais da SDS são de alta resolução. O MDT e o MDS são arquivos matriciais que possuem resolução de 1,0 metro. As imagens do sistema Sentinel a resolução espacial é de 10 metros. Estas resoluções espaciais altas possibilitaram um mapa síntese com nível de detalhamento de escala na ordem de $1 / 10.000$ considerando a área da bacia é um mapeamento temático promissor para a tomada de decisão.

A ponderação dos valores dos fatores hipsometria, declividade e uso e cobertura da terra, utilizados para mapear as áreas suscetíveis a inundação, foi realizada considerando a metodologia proposta por Caprario (2017), Caprario et al. (2019) e Caprario e Finotti (2019). Neste trabalho, adaptou-se a metodologia citada, acrescentando ordem dos rios (baseada nas ottobacias), como condicionante ao mapeamento de áreas suscetíveis a inundação. Para sintetizar as etapas de trabalho, foi elaborado um fluxograma, representado na Figura 2.

Figura 2 - Fluxograma descritivo das etapas do mapeamento das áreas suscetíveis à inundação.

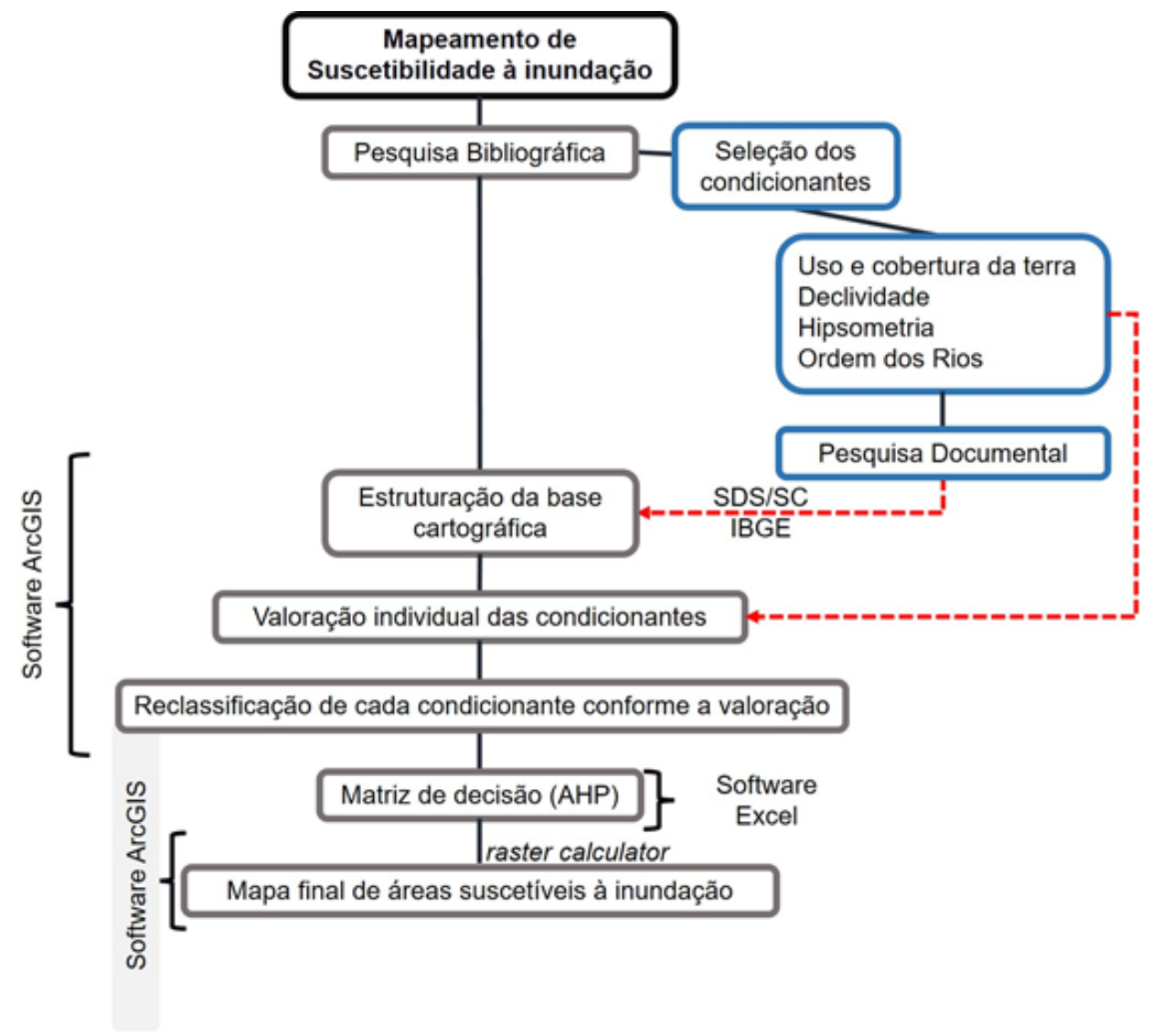

Fonte - Autores (2020).

Caminhos de Geografia Uberlândia-MG $\quad$ v. 22, n. $83 \quad$ out./2021 p. 160-175 Página 163




\section{Mapa temático de uso e cobertura da terra}

O mapa temático de uso e cobertura da terra na bacia hidrográfica, empregado neste trabalho, foi resultado de um estudo realizado por Dutra et al., (2017). A imagem utilizada foi do sistema sensor Sentinel-2 bandas 3, 4 e 8 que foram classificadas pelo método de máxima verossimilhança (DUTRA et al., 2017). O mapa de uso e cobertura da terra foi dividido em seis classes: área antropizada, área minerada, área urbanizada, campos de duna, massa de água e vegetação arbóreo-arbustiva (Figura 3). O Quadro 1 apresenta as classes de uso e cobertura da terra, com suas respectivas descrições e valoração.

Figura 3 - Mapa temático de uso e cobertura da terra da BHRU.

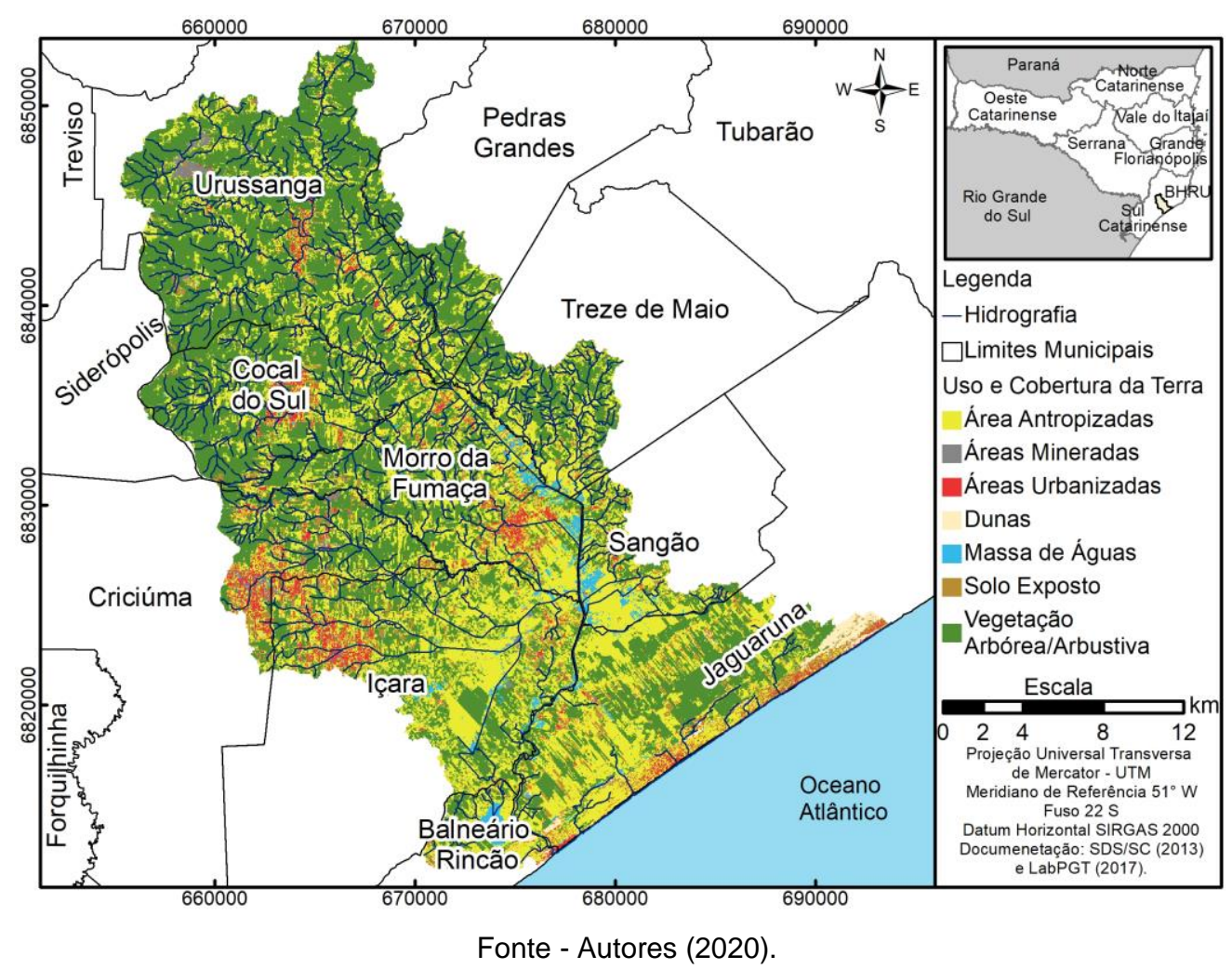

Quadro 1 - Classificação, descrição e valoração das classes do condicionante uso e cobertura da terra.

\begin{tabular}{|c|c|c|c|}
\hline Condicionante & $\begin{array}{l}\text { Classes de uso e } \\
\text { cobertura da terra }\end{array}$ & Descrição & Valores \\
\hline \multirow{7}{*}{$\begin{array}{l}\text { Mapa temático de } \\
\text { uso e cobertura da } \\
\text { terra }\end{array}$} & Área antropizada & Áreas agricultáveis e de pecuária e vazios urbanos & 7 \\
\hline & Área minerada & $\begin{array}{l}\text { Áreas com mineração de argila, basalto e carvão } \\
\text { mineral }\end{array}$ & 5 \\
\hline & Área urbanizada & $\begin{array}{l}\text { Área urbana residencial, comercial e de serviços, a } \\
\text { área urbana industrial, área urbana de uso misto e as } \\
\text { áreas periurbanas }\end{array}$ & 9 \\
\hline & Dunas $^{11}$ & Áreas próximas ao litoral com presença de dunas & 3 \\
\hline & Massa de água & Rios, lagoas e açudes & 10 \\
\hline & $\begin{array}{c}\text { Vegetação } \\
\text { arbórea/arbustiva }\end{array}$ & $\begin{array}{l}\text { Compreende as formações de florestas secundárias, } \\
\text { reflorestamento e silvicultura }\end{array}$ & 2 \\
\hline & Solo exposto & $\begin{array}{l}\text { Áreas em que a cobertura vegetal foi removida pelo } \\
\text { uso antrópico, como áreas erodidas pelo processo de } \\
\text { voçorocamento }\end{array}$ & 8 \\
\hline
\end{tabular}

Fonte - Autores (2020).

1 As dunas são formadas pela ação dos ventos, não são consideradas solo, mas como um tipo de terreno (SANTOS et al., 2018).

Caminhos de Geografia

Uberlândia-MG

v. 22, n. 83

out./2021

p. 160-175

Página 164 


\section{Mapa temático de declividade}

O mapa de declividade foi elaborado a partir do arquivo matricial MDT com uso do software ArcGis versão 10.3.1, disponibilizado nos laboratórios da Universidade do Extremo Sul Catarinense (ESRI, 2019). As classes do mapa de declividade foram definidas segundo orientação da Embrapa (2006). Assim a declividade da bacia hidrográfica do rio Urussanga foi classificada em seis classes distintas de relevo (Figura 4). Na Tabela 1, podem-se verificar as classes de declividade, as descrições do relevo e a valoração.

Figura 4 - Mapa temático de declividade da BHRU.

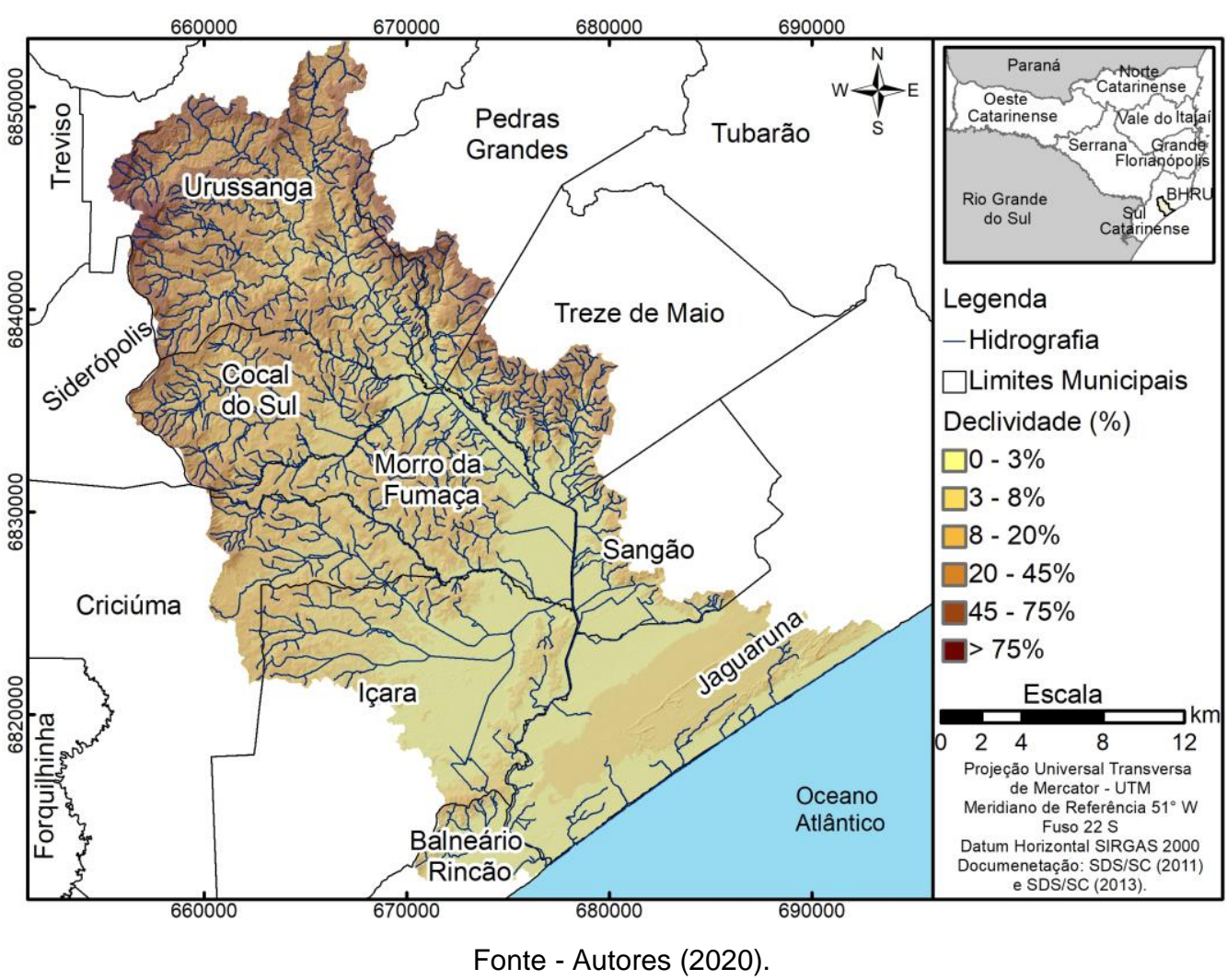

Tabela 1 - Classificação e valoração das classes do fator declividade.

\begin{tabular}{|c|c|c|c|c|}
\hline Condicionante & \multicolumn{3}{|c|}{ Classes de declividade } & Valores \\
\hline \multirow{7}{*}{$\begin{array}{l}\text { Mapa temático } \\
\text { de declividade }\end{array}$} & $\begin{array}{c}\text { Porcentagem } \\
(\%)\end{array}$ & $\begin{array}{c}\text { Declividade } \\
\text { média } \\
\text { (graus) }\end{array}$ & $\begin{array}{l}\text { Descrição } \\
\text { do relevo }\end{array}$ & \multirow[t]{2}{*}{10} \\
\hline & $0-3 \%$ & $0,85^{\circ}$ & $\begin{array}{c}\text { Terreno } \\
\text { plano }\end{array}$ & \\
\hline & $3-8 \%$ & $3,15^{\circ}$ & $\begin{array}{c}\text { Terreno } \\
\text { suavemente } \\
\text { ondulado }\end{array}$ & 9 \\
\hline & $8-20 \%$ & $7,95^{\circ}$ & $\begin{array}{c}\text { Terreno } \\
\text { ondulado }\end{array}$ & 6 \\
\hline & $20-45 \%$ & $17,8^{\circ}$ & $\begin{array}{c}\text { Terreno } \\
\text { fortemente } \\
\text { ondulado }\end{array}$ & 4 \\
\hline & $45-75 \%$ & $31^{\circ}$ & $\begin{array}{c}\text { Terreno } \\
\text { montanhoso }\end{array}$ & 2 \\
\hline & $>75 \%$ & $>37^{\circ}$ & $\begin{array}{c}\text { Terreno } \\
\text { fortemente } \\
\text { montanhoso }\end{array}$ & 1 \\
\hline
\end{tabular}

Fonte - Autores (2020). 
Marlon Domingos Cury

Nilzo Ivo Ladwig

Mapeamento de áreas suscetíveis à inundação como informação para o

planejamento e a gestão territorial em bacia hidrográfica

\section{Mapa temático de hipsometria}

Para a elaboração do mapa hipsométrico utilizou-se o MDT. Para a representação do terreno, a bacia foi dividida em classes com intervalos, equidistantes de 50 metros de altitude. Assim foram obtidas doze classes, que variam de 0 a 600 metros de altitude (Figura 5). Os intervalos de classe do mapa hipsométrico basearam-se em uma divisão em iguais intervalos de classe a partir da altitude mínima local até a altitude máxima. As classes de altitude e a valoração estão sintetizadas na Tabela 2.

Figura 5 - Mapa temático de hipsometria da BHRU.

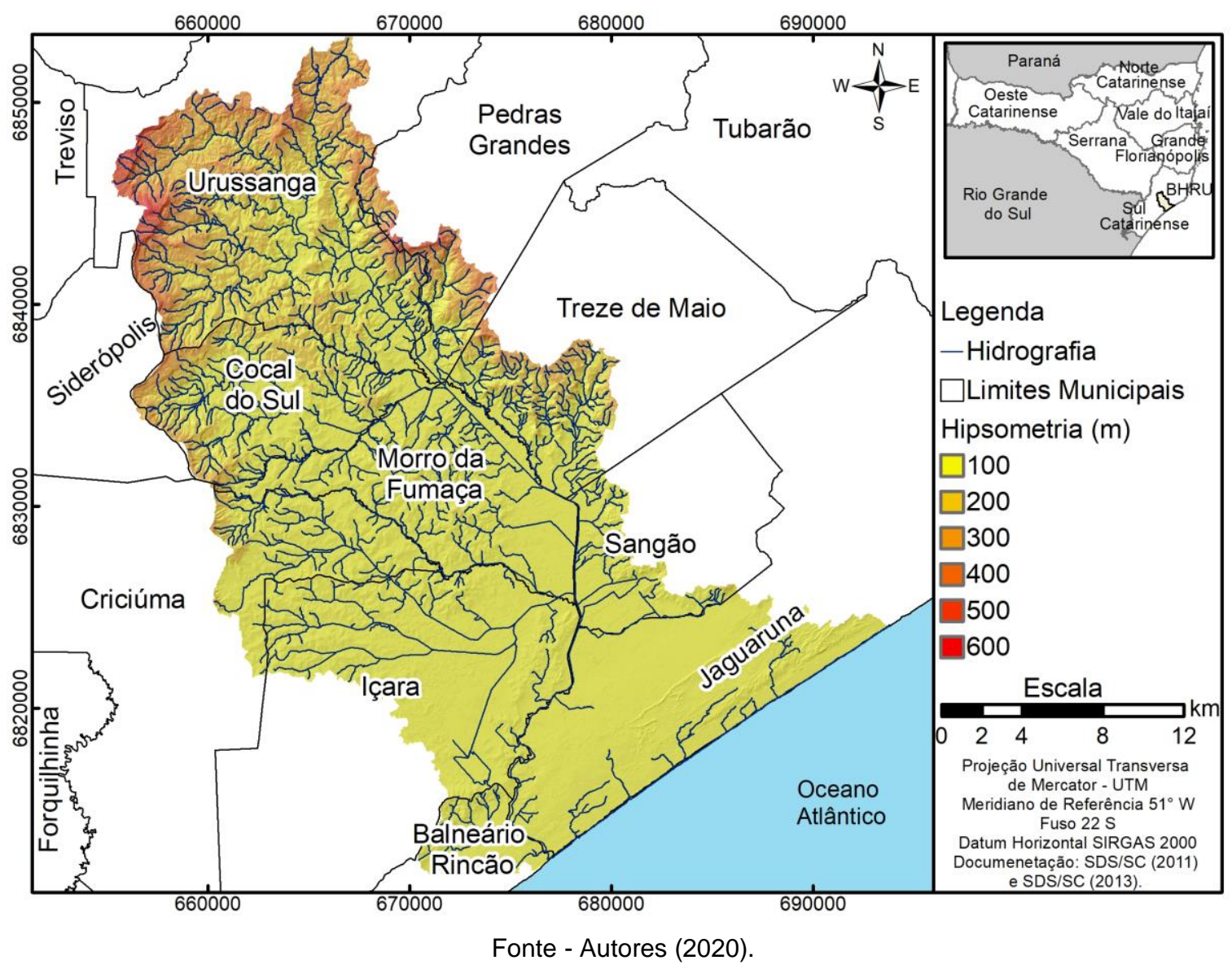

Tabela 2 - Classificação e ponderação das classes de altimetria.

\begin{tabular}{clcc}
\hline \multicolumn{4}{c}{ Fator } \\
\hline \multicolumn{4}{c}{ Mapa Hipsométrico } \\
\hline Classes de altitude & Valores & Classes de altitude & Valores \\
$0-50$ & 10 & $300-350$ & 5 \\
$50-100$ & 9 & $350-400$ & 4 \\
$100-150$ & 9 & $400-450$ & 3 \\
$150-200$ & 8 & $450-500$ & 2 \\
$200-250$ & 7 & $500-550$ & 2 \\
$250-300$ & 6 & $550-600$ & 1 \\
\hline
\end{tabular}

Fonte - Autores (2020).

$\begin{array}{lllll}\text { Caminhos de Geografia } \quad \text { Uberlândia-MG } & \text { v. 22, n. } 83 & \text { out./2021 } & \text { p. 160-175 } & \text { Página } 166\end{array}$




\section{Mapa temático de ordem dos rios das ottobacias}

Para a elaboração do mapa de ordem dos rios foi utilizado o Modelo Digital do Terreno (MDT), com o auxílio da ferramenta Archydro do software ArcGis versão 10.3.1, foram delimitadas as ottobacias pertencentes BHRU. Após, foi realizada a categorização dos cursos hídricos, utilizando o método de Strahler (1952). Com as ottobacias e os cursos de água foi possível ordenar as ottobacias com base na ordem dos rios (Figura 6).

A valoração das ordens das ottobacias foi baseada no estudo de Robaina, Kormann e Schirmer (2013). Os autores ressaltam que os canais de menor ordem proporcionam suscetibilidade de inundação relativamente baixa, quando comparados aos canais de maior ordem. Entretanto, de acordo com Cunha et al. (2012), todos os cursos de água colaboram para a ocorrência de cheias e inundações, pois o transbordo e consequente alagamento dos terrenos ribeirinhos compõem um processo natural, associado a todos os cursos de água. Desta forma, foi atribuído maior valor aos canais de maior ordem (Tabela 3 ).

Figura 6 - Mapa temático de ordem dos rios das ottobacias da BHRU.

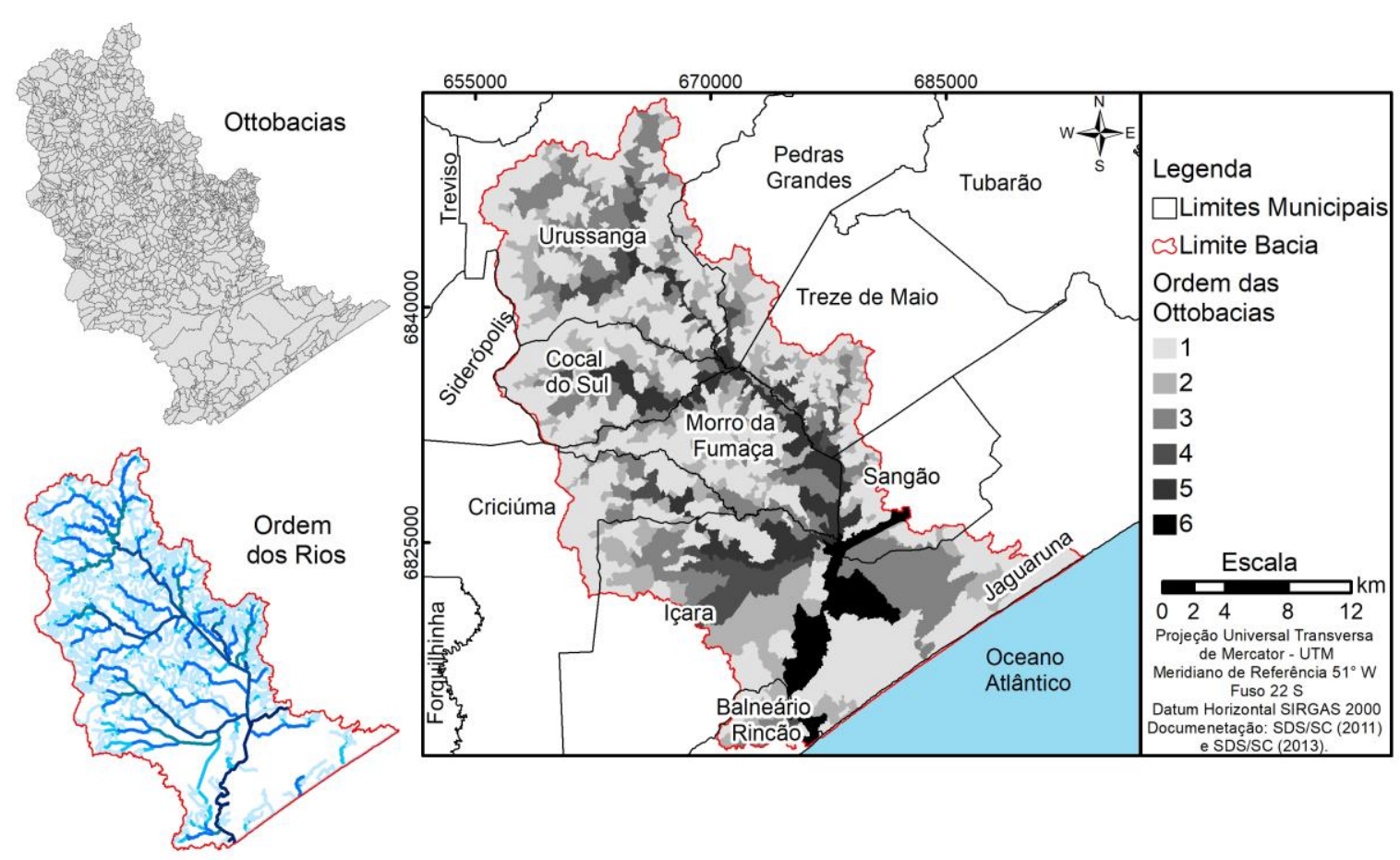

Fonte - Autores (2020).

Tabela 3 - Classificação e valoração das classes de ordem dos rios das ottobacias.

\begin{tabular}{cccc}
\hline \multicolumn{4}{c}{ Condicionante } \\
\hline $\begin{array}{c}\text { Ordem das } \\
\text { ottobacias }\end{array}$ & Valores & $\begin{array}{c}\text { Ordem das } \\
\text { ottobacias }\end{array}$ & Valores \\
\hline Ordem 1 & 1 & Ordem 4 & 6 \\
Ordem 2 & 2 & Ordem 5 & 8 \\
Ordem 3 & 4 & Ordem 6 & 10 \\
\hline
\end{tabular}

Fonte - Autores (2020). 
A etapa seguinte consistiu em realizar o processo de reclassificação de cada condicionante, conforme a valoração já apresentada. Este processo de reclassificação foi realizado por meio da ferramenta Reclassif, disponível no software ArcGis versão 10.3.1.

Após a reclassificação, foi elaborada uma matriz de decisão $(\mathrm{AHP})^{2}$, utilizando a escala fundamental proposta por Saaty (1980) (Quadro 2), definindo assim a importância entre os condicionantes, para tal utilizou-se o software Excel, disponibilizado nos laboratórios da Universidade do Extremo Sul Catarinense (MICROSOFT OFFICE, 2019).

Quadro 2 - Matriz de decisão.

\begin{tabular}{|c|c|c|c|c|}
\hline Variáveis & Declividade & Altimetria & Ordem dos rios & $\begin{array}{c}\text { Uso e cobertura } \\
\text { da terra }\end{array}$ \\
\hline Declividade & 1 & 2 & 2 & 2 \\
\hline Altimetria & 0,5 & 1 & 0,33 & 2 \\
\hline Ordem dos rios & 0,5 & 3 & 0,5 & 1 \\
\hline $\begin{array}{c}\text { Uso e cobertura } \\
\text { da terra }\end{array}$ & 0,5 & 0,5 & 3,83 & 7 \\
\hline Soma & 2,5 & 6,5 & & \\
\hline
\end{tabular}

Observa-se no Quadro 2 que a declividade é o fator de maior peso, sendo moderadamente mais importante que os outros fatores, isto se deve ao fato dela ser responsável pela força do escoamento da água. O segundo fator a exercer maior influência é a ordem dos rios, isto porque em rios de ordens maiores, haverá uma maior concentração de água e, consequentemente, uma maior suscetibilidade a inundação.

O fator altimetria exerce maior influência do que o uso e cobertura da terra, pois altitudes mais baixas associadas a baixas declividades aumentam a probabilidade de ocorrer o evento de inundação, sendo o fator uso e cobertura da terra considerado o menos influente.

Após a elaboração da matriz de decisão, foi possível obter o peso para cada condicionante. Para isto foi necessário realizar a divisão de cada fator pela somatória dos elementos da coluna a que pertence, em seguida é calculada uma média entre as linhas, obtendo-se, então, os pesos de cada fator.

Para a validação do método foi necessário calcular a razão de consistência. O valor de consistência encontrado foi de 0,082, indicando que os pesos calculados são aceitáveis. Na Tabela 6 são apresentados os pesos dos condicionantes. O condicionante de maior contribuição para a ocorrência de inundações foi a declividade, seguida pela ordem dos rios, altitude e uso e cobertura da terra.

Tabela 6 - Pesos dos critérios.

\begin{tabular}{cc}
\hline Condicionantes & Pesos \\
\hline Uso e ocupação da terra & 0,1406 \\
Ordem dos rios & 0,3068 \\
Declividade & 0,3835 \\
Hipsométrico & 0,1752 \\
\hline
\end{tabular}

Fonte - Autores (2020).

2 A AHP (Analytic Hierarchy Process) consiste na elaboração de uma hierarquia de decisão, em que possível visualizar o processo de maneira geral. Ao determinar a importância de cada fator, são gerados os pesos deles. Assim, os resultados das matrizes são ponderados entre si (SILVA e NUNES, 2009).
Caminhos de Geografia
Uberlândia-MG
v. 22, n. 83
out./2021
p. 160-175
Página 168 
Após a definição de todos os critérios e seus respectivos pesos, foi elaborado o mapa temático de suscetibiliddae à inundação da bacia. Para isso, foi utilizado o software ArcGis versão 10.3.1, ferramenta raster calculator, em que os pesos são multiplicados por cada mapa, conforme equação seguinte:

VI: $0.1406{ }^{*} U+0.3835^{\star} D+0.1752^{*} A+0.3068^{*} O R$

Em que:

VI: vulnerabilidade à inundação | U: Mapa de uso e cobertura da terra

D: Mapa de declividade | A: Mapa hipsométrico | OR: Mapa ordem dos rios.

\section{DISCUSSÃO DOS RESULTADOS}

O mapa temático de áreas suscetíveis a inundação, foi dividido em três classes, de acordo com os graus de suscetibilidade da área ao fenômeno de inundação: baixa suscetibilidade, média suscetibilidade, alta suscetibilidade (Figura 7). O mapa foi dividido de acordo com o método de intervalos iguais. As respectivas áreas das classes de suscetibilidade à inundação estão distribuídas na Tabela 5.

Figura 7 - Mapa das áreas suscetíveis à inundação da BHRU.

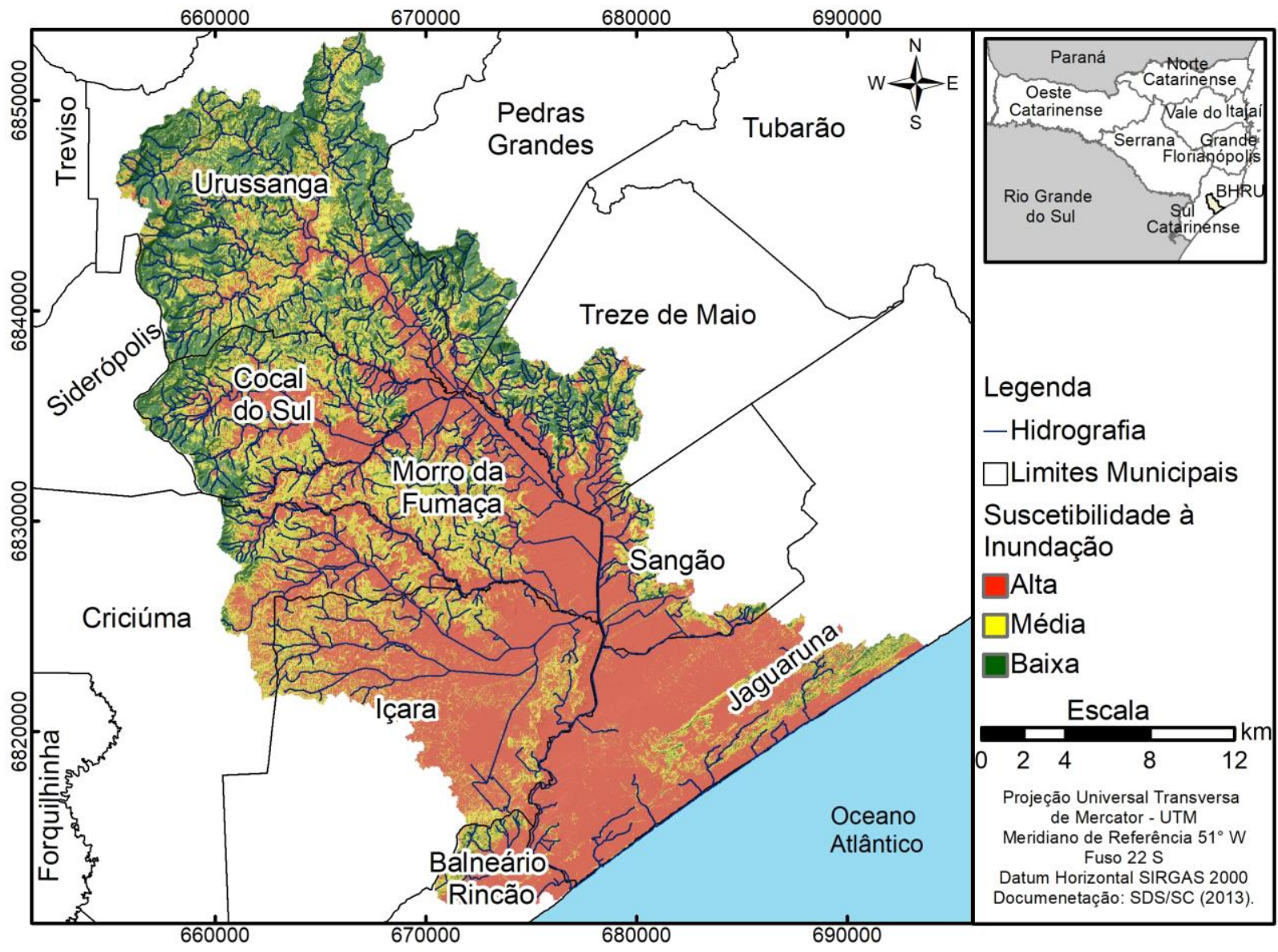

Fonte - Autores (2020).

$\begin{array}{lllll}\text { Caminhos de Geografia } \quad \text { Uberlândia-MG } & \text { v. 22, n. } 83 & \text { out./2021 } & \text { p. 160-175 Página } 169\end{array}$


Tabela 5 - Áreas das classes de suscetibilidade a inundação.

\begin{tabular}{ccc}
\hline Classes & Área $\left.\mathbf{( k m}^{2}\right)$ & $\%$ \\
\hline Baixa suscetibilidade & 135,107 & 19,95 \\
Média suscetibilidade & 339,667 & 50,16 \\
Alta suscetibilidade & 202,349 & 29,89 \\
\hline
\end{tabular}

Fonte - Autores (2020).

A menor porção da BHRU está inserida em áreas de baixa suscetibilidade à inundação, ocupando 135,107 km² $^{2}(19,95 \%)$, localizadas nas linhas divisoras de água da bacia, onde predominam grandes altitudes e declividades, abrangendo partes dos municípios de Cocal do Sul, Treze de Maio, Urussanga e Pedras Grandes. Conforme Muller (2012) e Prochmann (2014), em grandes declives a velocidade do escoamento superficial é maior e, consequentemente, a capacidade de infiltração da água no solo é menor, contribuindo diretamente com o acúmulo de água nas áreas mais planas.

As regiões de maior altitude da bacia são cobertas, em sua maioria, por vegetação arbóreo/arbustiva. A cobertura vegetal reduz o escoamento superficial da água da chuva, propiciando a sua infiltração no solo (TUCCI, 2007). Além disso, ressalta-se que nas áreas mais íngremes da bacia destacam-se os rios de baixa ordem, que pouco influencia no processo de inundação (ROBAINA; KORMANN; SCHIRMER, 2013)

As áreas de média suscetibilidade à inundação ocupam a maior parte do território da BHRU, com $339,667 \mathrm{~km}^{2}$, totalizando $50,16 \%$ da bacia, localizadas principalmente nos municípios de Urussanga e Cocal do Sul. As áreas de média suscetibilidade são caracterizadas por apresentarem intensa antropização, marcadas pela presença de agricultura, pecuária e vazios urbanos. Além disso, a declividade e a altitude começam a diminuir.

Parte significativa da BHRU, 29,88\% $\left(202,349 \mathrm{~km}^{2}\right)$, encontra-se em áreas de alta suscetibilidade à inundação, ocupando o fundo dos vales até a faixa litorânea da bacia, com destaque para os municípios de Jaguaruna, Sangão, Morro da Fumaça, Criciúma e Içara. Essas áreas encontram-se majoritariamente nas regiões de menores altitudes e declividades.

As áreas com maior suscetibilidade à ocorrência de inundações estão associadas às cotas altimétricas mais baixas (TUCCI, 2009; CHAVES e PEIXOTO FILHO, 2015). Considerando as recomendações de Magalhães et al. (2011), o acúmulo de água no solo é diretamente influenciado pela declividade, pois as regiões planas apresentam escoamento superficial com baixa velocidade e, consequentemente, a capacidade de transporte fica limitada à vazão de escoamento, aumentando a probabilidade de ocorrência de inundações.

O estudo de Souza (2005) apontou que as bacias hidrográficas com maior suscetibilidade a inundação apresentam como característica ordem hierárquica dos rios entre 3 e 7 . Ao comparar as figuras 6 e 7, confirma-se que as ottobacias da BHRU, que apresentam ordem dos rios superior a 3 , estão localizadas em áreas de alta suscetibilidade a inundação. A autora ainda afirma que as bacias hidrográficas de regiões costeiras apresentam condicionantes muito propícios à ocorrência de inundações, pois as áreas de captação estão situadas em terrenos de maior declividade, enquanto as demais áreas da bacia estão situadas em terrenos relativamente planos. Desta forma, os rios localizados em planícies costeiras, recebem um grande volume de água das encostas, porém a velocidade de escoamento diminui por conta da baixa declividade e o represamento das marés (SOUZA, 2005).

A ordem dos rios, além de refletir o comportamento do escoamento, quando relacionada aos diversos processos superficiais, adquire grande importância como instrumento de análise da paisagem, exercendo um papel importante para a elucidação da dinâmica da bacia hidrográfica, uma vez que seu estudo permite evidenciar a atuação de certos controles como clima, vegetação, litologia e outros fatores que caracterizam a área drenada.

Segundo Dias et al. (2009), devido à localização geográfica de Santa Catarina, vizinha ao Oceano Atlântico, o estado possui condições de receber grande quantidade de umidade, por meio da brisa

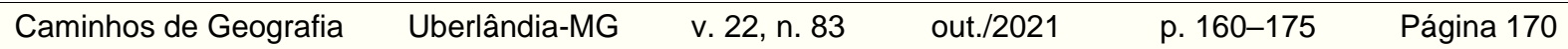


marítima. Associado a isso, o desenho da costa, sem golfos ou baías, que limitam a ação das marés, favorece a ação de represamento do fluxo de água vindo do continente por meio dos rios, potencializando o risco de inundações.

Ainda, de acordo com Dias et al. (2009), a região costeira do estado de Santa Catarina, localizada entre o Oceano Atlântico e o Planalto da Serra Geral, está submetida a processos naturais de denudação que, dadas as condições climáticas, geológicas, geomorfológicas e de uso e cobertura da terra se constitui em área com alto risco de ocorrência de desastres naturais na forma de inundações e corridas de massa.

Em sua pesquisa sobre os aspectos da paisagem oleira de Morro da Fumaça Cunha (2002), afirma que a extração inadequada de argilas depositadas nas planícies de inundação com a posterior extração de areia acarretou em uma grande quantidade de escavações sem a adequação com a legislação, contribuindo para o evento de inundação, pois há muitas cavas próximas umas das outras, já inundadas por água da precipitação e/ou água do lençol freático.

Nas áreas com maior suscetibilidade à inundação, predominam as classes de uso e cobertura da terra, área antropizada e área urbanizada, que juntas somam 41,4\% (281,700 km2). Segundo Magalhães et al. (2011) e Ouma e Tateishi (2014), as conformações de uso e cobertura da terra influenciam nos processos de infiltração e escoamento superficial, aumentando a vazão de pico e, consequentemente, propiciando a ocorrência de inundações. Nesse contexto, pode-se considerar que nas áreas urbanizadas, devido à impermeabilização do solo, há diminuição da infiltração e aumento do escoamento superficial, ocasionando inundações.

De acordo com Borges (2013), ações antrópicas podem potencializar ou acelerar os processos de inundação, como as obras de retificação, desvios e canalização dos cursos d'água, além da impermeabilização do solo. Nos estudos de Cury (2018), os municípios de Jaguaruna, Sangão, Morro da Fumaça, Criciúma e Içara, que possuem extensões urbanas inseridas nas áreas com alta suscetibilidade na BHRU, emitiram entre os anos de 1998 e 2017, 56 decretos associados à inundação, enxurradas ou chuvas intensas, sendo classificados como situação de emergência. Além do grande adensamento populacional ocasionado pela urbanização das cidades inseridas na bacia, vários rios tiveram suas características naturais alteradas decorrentes de intervenções antrópicas realizadas, contribuindo para as inundações.

De acordo com Maffra e Mazzola (2007), no Brasil há uma relação muito forte entre o avanço da degradação ambiental, a intensidade do impacto dos desastres e o aumento da vulnerabilidade humana. A urbanização ao longo das planícies fluviais é um processo histórico, consequência das facilidades geradas para o estabelecimento de atividades agrícolas e para utilização dos cursos hídricos para diversos fins, porém, quando estas atividades são associadas aos cursos hídricos produzem riscos para a drenagem, acarretando a poluição da água e o agravamento do fenômeno de inundação, pois apresentam grandes áreas de solos impermeabilizados, o que reduz a infiltração das águas pluviais e aumenta o escoamento superficial, tal fato, aliado à ausência de planejamento e gestão eficiente, aumenta a vulnerabilidade ao risco de inundação.

\section{CONSIDERAÇÕES FINAIS}

A utilização da metodologia proposta para a determinação de pesos dos condicionantes, considerados influentes na delimitação de áreas suscetíveis à inundação, se mostrou eficaz, uma vez que a razão de consistência encontrada foi de 0.082 .

O fator ordem dos rios revelou-se eficiente na identificação das áreas suscetíveis à inundação, já que as regiões próximas aos cursos hídricos de maior ordem apresentam maior suscetibilidade, favorecendo a inundação e aumentando a confiabilidade aos resultados obtidos.

O mapeamento de suscetibilidade à inundação em bacia hidrográfica possibilitou definir as áreas mais propensas a este fenômeno, indicando áreas prioritárias para a realização de políticas públicas e ações para a prevenção e mitigação dos efeitos das inundações.

Conclui-se que aproximadamente $30 \%$ BHRU possui um grau suscetibilidade à inundação alto. Resultado que pode auxiliar no planejamento e na gestão territorial dos municípios. Resta concluir

$\begin{array}{lllll}\text { Caminhos de Geografia } & \text { Uberlândia-MG } & \text { v. 22, n. } 83 & \text { out./2021 } & \text { p. 160-175 }\end{array}$ Página 171


que o uso de ferramentas de geoprocessamento é importante nos estudos sobre suscetibilidade, pois oferecem subsídios ao planejamento e a gestão territorial no quesito prevenção que sejam eficazes e compatíveis com os anseios da população.

\section{AGRADECIMENTOS}

A Diretoria de Pesquisa e Pós-Graduação da Universidade do Extremo Sul Catarinense - UNESC pela bolsa concedida durante o desenvolvimento da pesquisa no Programa de Pós Graduação em Ciências Ambientais - PPGCA.

\section{REFERÊNCIAS}

AMARAL, Rosangela do; RIBEIRO, Rogério Rodrigues. Inundação e Enchentes. In: TOMINAGA, L. K.; SANTORO, J.; AMARAL, R (Org.). Desastres Naturais: conhecer para prevenir. 2 ed. São Paulo: Instituto Geológico, 2012. p. 39-52.

ASSAD, Eduardo Delgado; SANO, Edson Eyji. Sistemas de informações geográficas: Aplicações na Agricultura. 3.ed. Brasília: SPI/EMBRAPA-CPAC, 2003. 434 p.

BACK, Álvaro José. Caracterização climática. In: MILIOLI, G; SANTOS, R.; CITADINI-ZANETTE, V (Org.). Mineração de carvão, meio ambiente e desenvolvimento sustentável no sul de Santa Catarina. Curitiba: Juruá, 2009. p. 17-33.

BORGES, Naiany Silva. Gestão Do Risco De Inundações Urbanas. 2013. 101f. Dissertação (Mestrado em Direito) - Universidade de Coimbra, Coimbra, 2013.

CAPRARIO, Jakcemara. Desenvolvimento de um instrumento para o mapeamento de áreas suscetíveis a alagamentos e inundações urbanas. 2017. 223f. Dissertação (Mestrado em Engenharia Ambiental) - Universidade Federal de Santa Catarina, Florianópolis, 2017.

CAPRARIO, Jakcemara; FINOTTI, Alexandra Rodrigues. Socio-technological tool for mapping susceptibility to urban flooding. Journal Of Hydrology, v. 574, p. 1152-1163, abr. 2019.

https://doi.org/10.1016/j.jhydrol.2019.05.005

CAPRARIO, Jakcemara; RECH, Aline Schuck; TASCA, Fabiane Andressa; FINOTTI, Alexandra Rodrigues. Influence of drainage network and compensatory techniques on urban flooding susceptibility. Water Science \& Technology, Londres, v. 79, n. 6, p. 1152-1163, mar. 2019. https://doi.org/10.2166/wst.2019.113

CHAVES, Ian Souza Bandeira; PEIXOTO FILHO, Getúlio Ezequiel. Identificação de áreas suscetíveis à ocorrência de inundações na Região Administrativa Fercal (RA XXXI).SIMPÓSIO BRASILEIRO DE SENSORIAMENTO REMOTO - SBSR, 17., 2015. João Pessoa - PB. Anais .... São José dos Campos: INPE, 2015. Disponível em: < http://www.dsr.inpe.br/sbsr2015/files/p1546.pdf>. Acesso em: 20 de jan. 2017.

CUNHA, Lúcio; LEAL, Cátia; TAVARES, Alexandre; SANTOS, Pedro. Risco de inundação no município de Torres Nova (Portugal). Revista Geonorte, Manaus, ed. Especial, n. 4, p. 961-973. 2012.

CUNHA, Yasmine Moura. Aspectos da paisagem oleira de Morro da Fumaça (SC). 2002. 249f. Dissertação (Mestrado em Geografia) - Universidade Federal de Santa Catarina, Florianópolis, 2002.

CURY, Marlon Domingos. Análise do risco e vulnerabilidade á inundação na bacia hidrográfica do Rio Urussanga. 2018. 131 f. Dissertação (Mestrado) - Programa de Pós-graduação em Ciências Ambientais, Universidade do Extremo Sul Catarinense - Unesc, Criciúma, 2018.

DANTAS, Camila Galindo. Experiências e aprendizado: Rio Aricanduva: prevenção, resposta e mitigação. In: Melhor prevenir: Olhares e saberes para a redução de risco de desastre. SULAIMAN, Samira Nascimento; JACOBI, Pedro Roberto. São Paulo: IEE-USP, 2018.

Caminhos de Geografia Uberlândia-MG $\quad$ v. 22, n. 83 out./2021 p. 160-175 Página 172


DIAS, Maria Assunção Faus da Silva; NOBRE, Carlos; ORSINI, José Antonio Marengo; RODRIGUES, Maria Lauro Guimarães; LIMA, Marilene de; MINUZZI, Rosandro Boligon. As chuvas de novembro de 2008 em Santa Catarina: um estudo de caso visando a melhoria do monitoramento e da previsão de eventos extremos. Cachoeira Paulista: CPTEC/INPE, 2009.

DUTRA, Letícia da Costa; CONTO, Danrlei de; SUTIL, Thaise; LADWIG, Nilzo Ivo. Mapeamento de uso e cobertura da terra na bacia hidrográfica do Rio Urussanga utilizando imagens orbitais de diferentes sistemas sensores. In: Semana de Ciência e Tecnologia, 7., 2017, Criciúma. Anais [...] . Criciúma: Unesc, 2017. p. 1-2.

EMBRAPA - Empresa Brasileira de Pesquisa Agropecuária. Sistema Brasileiro de classificação de solos. 2ª edição. Rio de Janeiro: Embrapa Solos, 2006.

ESRI - Environmental Systems Research Institute. Software ArcGis 10.3.1.4959 for Desktop

Educacional em Rede. Disponível nos laboratórios da Universidade do Extremo Sul Catarinense, 2019.

IBGE - Instituto Brasileiro de Geografia e Estatística. Manual técnico da vegetação brasileira. Rio de Janeiro, 92p. 2012.

IBGE - Instituto Brasileiro de Geografia e Estatística. Provedor de informações geográficas e estatísticas do Brasil. Disponível em: https://www.ibge.gov.br/geociencias/downloads-geociencias.html - Acesso em: 10, jan. 2018.

LADWIG, Nilzo Ivo; GONÇALVES, Teresinha Maria. Mapeamento de áreas de risco uma necessidade na Gestão Territorial. In: LADWIG, Nilzo Ivo; SCHWALM, Hugo. (Org.). Planejamento e Gestão Territorial: reflexões interdisciplinares. Florianópolis: Insular, 2014. p.149-178.

LADWIG, Nilzo Ivo; ROSSO, Edgar Piacentini. Geoprocessamento aplicado no mapeamento de áreas de risco. In: Nilzo Ivo Ladwig; Hugo Schwalm. (Org.). Planejamento e Gestão Territorial: Experiências Sustentáveis. Florianópolis: Insular, 2015, p. 57-76.

MAFFRA, C. Q. T., MAZZOLA, M. As razões dos desastres em território brasileiro. In: R. F. Santos (Org.), Vulnerabilidade ambiental: desastres naturais ou fenômenos induzidos?. Brasília: Ministério do Meio Ambiente. 2007, p. 10-12.

MAGALHÃES, Ivo Lopes; THIAGO, Carlos Roberto; AGRIZZI, Daniela Vantill; SANTOS, Alexandre Rosa dos. Uso de geotecnologias para mapeamento de áreas de risco de inundação em Guaçuí, ES: uma análise comparativa entre dois métodos. Cadernos de Geociência, Salvador, v. 8, n. 2, p. 63 - 70. 2011.

MENEGASSO, Juliana Debiasi. Mapeamento do risco de inundação na bacia hidrográfica do Rio Belo, Orleans, SC. 2019. 148 f. Dissertação (Mestrado) - Programa de Pós-graduação em Ciências Ambientais, Universidade do Extremo Sul Catarinense - Unesc, Criciúma, 2019.

MENEZES, Afonso Henrique Novaes; DUARTE, Francisco Ricardo; CARVALHO, Luis Osete Ribeiro; SOUZA, Tito EugÊnio Santos. Metodologia científica teoria e aplicação na educação a distância. Petrolina: Univasf, 2019.

MENEZES, Carlyle Torres Bezerra de; WATERKEMPER, Kátia. Evolução dos processos de degradação ambiental resultante da mineração de carvão em Santa Catarina de 1930-1973. In: MILIOLLI, G.; SANTOS, R.; CITADINI-ZANETTE, V. (Org.). Mineração de carvão, meio ambiente e desenvolvimento sustentável no sul de Santa Catarina: uma abordagem interdisciplinar. Curitiba: Juruá, 2009. p. 2052013.

MICROSOFT OFFICE. Software Excel 2019. Contrato OVS microsoft com Fucri - UNESC com vencimento em 30/11/2021.

MORIN, Edgar. Introdução ao pensamento complexo. 4. ed. Porto Alegre: Sulina, 2011

$\begin{array}{lllll}\text { Caminhos de Geografia } & \text { Uberlândia-MG } & \text { v. 22, n. } 83 & \text { out./2021 } & \text { p. 160-175 }\end{array}$


MULLER, Cristiane Regina. Avaliação de suscetibilidade a inundações utilizando geotecnologias para a bacia hidrográfica do Rio Cachoeira - Joinville/SC. 2012. 117f. Dissertação (Mestrado em Planejamento Territorial e Desenvolvimento Socioambiental) - Universidade do Estado de Santa Catarina, Florianópolis, 2012

OUMA, Yo; TATEISHI, Ryutaro. Urban Flood Vulnerability and Risk Mapping Using Integrated MultiParametric AHP and GIS: Methodological Overview and Case Study Assessment. Water, [s.I.], v. 6, n. 6, p.1515-1545, 2014. https://doi.org/10.3390/w6061515

PANDOLFO, Cristina; BRAGA, Hugo José; SILVA JR, Vamilson Prudêncio da; MASSIGNAM, Angelo Mendes, PEREIRA, Emauela Salum; THOMÉ, Vera Magali Radtke; VALCI, Francisco Vieira. Atlas climatológico do Estado de Santa Catarina. Florianópolis: Epagri, 2002. CD-Rom.

PROCHMANN, João Ricardo. Análise especial da suscetibilidade à inundações na bacia hidrográfica do Córrego Grande, Florianópolis - SC. 2014. 88f. Trabalho de conclusão de curso (Graduação em Engenharia Sanitária e Ambiental) - Universidade Federal de Santa Catarina, Florianópolis, 2014.

PRODANOV, Cleber Cristiano; 2013, Ernani Cesar de Freitas Novo Hamburgo - Rio Grande do Sul Brasil. Metodologia do trabalho científico: Métodos e Técnicas da Pesquisa e do Trabalho Acadêmico. 2. ed. Novo Hamburgo: FEEVALE, 2013.

REIS, Janete Teresinha; SILVA, Jones; MICHEL, Gean Paulo; KOBIYAMA, Masato. Mapeamento da vulnerabilidade a desastres hidrológicos nos municípios de alto feliz e São Vendelino/RS como forma de contribuição à engenharia de sedimentos. In: ENCONTRO NACIONAL DE ENGENHARIA DE SEDIMENTOS, 11, João Pessoa -PB. Anais...João Pessoa: 2014, p.1-17.

ROBAINA, Luis Eduardo de Souza; KORMANN, Tanice Cristina; SCHIRMER, Gerson Jonas. Zoneamento das inundações na área urbana de Alegrete - Rio Grande do Sul - Brasil. Revista Geociências. São Paulo, v. 32, n.2. p. 346-355, 2013.

SAATY, Thomas Lorie. The Analytic Hierarchy Process. McGraw-Hill, New York, 1980. https://doi.org/10.21236/ADA214804

SANTA CATARINA (Estado). Lei n. 10.949, de 09 de novembro de 1998. Dispõe sobre a caracterização do Estado em 10 (dez) Regiões Hidrográficas. Disponível em:

<https://www.aguas.sc.gov.br/jsmallfib_top/DHRI/Legislacao/Lei-Estadual-10949-1998.pdf>. Acesso em 10 de jun. 2019.

SANTOS, Humberto Gonçalves dos; JACOMINE, Paulo Klinger Tito; ANJOS, Lúcia Helena Cunha dos; OLIVEIRA, Virlei Álvaro de; LUMBRERAS, José Francisco; COELHO, Maurício Rizzato; ALMEIDA, Jaime Antonio de; FILHO, José Coelho de Araújo; OLIVEIRA, João Bertoldo de; CUNHA, Tony Jarbas Ferreira. Sistema Brasileiro de Classificação de Solos. 5. ed. Brasília: Embrapa, 2018. 356 p.

SDS - Secretaria de Estado do Desenvolvimento Social. Governo do Estado de Santa Catarina. SIGSC: Sistema de Informações Geográficas do Estado de Santa Catarina, 2011 e 2013. Disponível em: http://www.sigsc.sds.sc.gov.br/download/index.jsp - Acesso em: 10, jan. 2018.

SILVA, Cristiano Alves da; NUNES, Fábio de Paiva. Mapeamento de vulnerabilidade ambiental utilizando o método AHP: uma análise integrada para suporte à decisão no município de Pacoti/CE. In: SIMPÓSIO BRASILEIRO DE SENSORIAMENTO REMOTO, 14., 2009, Natal, RN. Anais... São José dos Campos: INPE, 2009. p. 5435-5442.

SOUZA, Celia Regina de Gouveia. Suscetibilidade morfométrica de bacias de drenagem ao desenvolvimento de inundações em áreas costeiras. Revista Brasileira de Geomorfologia, v. 6, n.1. p. 45-61, 2005. https://doi.org/10.20502/rbg.v6i1.38

$\begin{array}{lllll}\text { Caminhos de Geografia } \quad \text { Uberlândia-MG } & \text { v. 22, n. } 83 & \text { out./2021 } & \text { p. 160-175 Página } 174\end{array}$


STRAHLER, A. N. Hypsometric (Area-altitude) analysis of erosional topography. Bull. G.S.A., v. 63, p. 1117-1142, 1952. https://doi.org/10.1130/0016-7606(1952)63[1117:HAAOET]2.0.CO;2

TUCCI, C. E. M. Urban Flood Management. Global Water Partnership, WMO - World Meteorologic Organisation, Cap-Net. Maio, 2007.

TUCCI, Carlos Eduardo Morelli. Hidrologia: ciência e aplicação. $2^{a}$ edição. Porto Alegre: Ed. Universidade/UFRGS/Associação Brasileira de Recursos Hídricos; 2009.

TUNDISI, José Galizia. Recursos hídricos no futuro: problemas e soluções. Estudos Avançados, São Paulo, v. 22, n. 63, p. 7-16, jan. 2008. ISSN 1806-9592. Disponível em: $<$ http://www.revistas.usp.br/eav/article/view/10290>. Acesso em: 12 jan. 2018. https://doi.org/10.1590/S0103-40142008000200002

UFSC - UNIVERSIDADE FEDERAL DE SANTA CATARINA. Relatório de danos materiais e prejuízos decorrentes de desastres naturais no Brasil: 1995 - 2014. 1 ed. Florianópolis: Ceped, 2016.

ZANELLA, Liane Carly Hermes. Metodologia de pesquisa. 2. ed. Florianópolis: UFSC, 2013.

Recebido em: 21/07/2020

Aceito para publicação em: 03/12/2020 